NGUYEN DAT MINH

DUONG TRUNG KIEN

TRUONG HUY HOANG

\title{
ENERGY BENCHMARKING MANAGEMENT FOR BEER AND BEVERAGE INDUSTRY IN VIETNAM
}

Nguyen Dat Minh, Ph.D., Electric Power University, Faculty of Industrial and Energy

Management,

Hanoi, Vietnam,

ID ORCID: 0000-0002-2267-4917.

Duong Trung Kien, Ph.D..

Electric Power University, Faculty of Industrial and Energy

Management,

Hanoi, Vietnam,

ID ORCID: 0000-0002-8591-2775.

Truong Huy Hoang, Ph.D. ,

Electric Power University,

Faculty of Industrial and Energy

Management,

Hanoi, Vietnam,

ID ORCID: 0000-0002-7019-5603.

\section{Introduction}

Energy efficiency management (EE) and saving is an important strategy to achieve decarbonization to achieve the objective of reduce $1.5^{\circ} \mathrm{C}$, energy consumption, and climate change (Labandeira, Labeaga, Linares, \& López-Otero, 2020). EE provides a very important role to contribute and ensure the security of energy supply and increase the competitiveness of businesses (Bertoldi \& Mosconi, 2020). EE is one of the core elements of the energy community, next to energy security, solidarity and trust. Besides, the benefits of $\mathrm{EE}$ including the reduction of emissions, enhanced competitiveness, health and economic benefits can be significantly higher than the cost of energy measures (Zhang et al., 2016).

Benchmarking is a systematic method of evaluation for products, services, and processes of organizations that are recognized as best or standard practices for the purpose of improvement (Stapenhurst, 2009). Benchmarking is a process of comparing 
between one's business performance metrics and the best practices from other business in the industry (S. C. Hui, 2010). Energy benchmarking is used as an EE instrument measurement (Zogla, Zogla, Beloborodko, \& Rosa, 2015), through detailed comparative analysis, the benchmarking process can identify areas for improving operations and management (Mull, 2001). Besides, energy benchmarking is becoming a critical methodology for the EE opportunity assessment and measures of reduce energy consumption at national, industry, and organization level (M. Hui \& Wong, 2010). The combination of different benchmarking instruments gives the best results to reach EE objectives, and the main measurement indicator of benchmarking in energy industry is specific energy consumption (SEC) (Tanaka, 2011; Zogla et al., 2015).

Vietnam has quite a comprehensive legislation in order to secure an EE industry. The Ministry of Industry and Trade (MOIT) and the provincial Departments of Industry and Trade (DOIT) are working together to enforce this legislation throughout the country. The Circular 19/2016/TT-BCT dated April, $19^{\text {th }} 2016$ on energy consumption quota in the beer and beverage production industry in Vietnam (Ministry of Industry and Trade, 2016). In accordance with Circular 19/2016/TT-BCT all enterprises in the beer and beverage production industry have to report on their SEC value to the DOIT every year (Assawamartbunlue \& Luknongbu, 2020). The SEC Target is the maximum allowable specific energy consumption for the site according to the LEEC-legislation. If the SEC value does not abide by the SEC targets set out in the Circular the enterprise additional have to report a plan on how to reach the SEC target in the future.

However, after six years of implementation the Circular No.19, the efficient of benchmarks on EE is very little, lack of understanding at DOIT and enterprise-level on benchmarks implementation. The impression is, that no real administration is enforced so far, and thus there is no challenge with the procedures - there are no real procedures. Therefore, this study introduces the methodology of benchmarking through SEC calculation supports the enterprise in how to determine the SEC target, the SEC value, investigate possible energy saving projects and making an implementation plan for the beer and beverage industry in Vietnam to meet the requirement of the national EE targets and implementing Circular No.19/2016/TT-BCT.

\section{Literature of energy benchmarking management}

Benchmarking is a methodology for the assessment of EE opportunities and referring to the comparison of energy consumption at facilities with similar 
characteristics, such as among plastic factories, steel manufacturers, or office buildings (M. Hui \& Wong, 2010). The purpose of energy benchmarking is abundant as this topic is closely related to studies on energy intensity, energy management and energy efficiency (Sontag et al., 2014). Through the detailed energy analysis, the benchmarking process can identify opportunities for operations and management improvement to reduce costs and improve service levels (Mull, 2001). The positive approaches of benchmarking are defined and calculated the standard of energy consumption based on the actual energy consumption, energy wastes analysis, and identify opportunities to save energy (Gruber, Fleiter, Mai, \& Frahm, 2011). By setup a suitable energy performance indicators as a energy benchmarking in organizations, it is possible to promote energy best practices and achieve better EE in their facilities (S. C. Hui, 2010).

SEC is a commonly used as EE performance indicators (Assawamartbunlue \& Luknongbu, 2020), it is the ratio between amount of energy consumption and production volume during the baseline period, which the amount of energy consumption requirement to complete a product (Assawamartbunlue, Surawattanawan, \& Luknongbu, 2019). The purpose of SEC is to identify potential of energy improvements. This is an important tool of energy management (Lawrence, Thollander, Andrei, \& Karlsson, 2019). SEC is used as an energy performance indicator to measure the performance of $\mathrm{EE}$ in both literature and practices (Farla, Blok, \& Schipper, 1997; Fleiter, Fehrenbach, Worrell, \& Eichhammer, 2012; Lawrence, Karlsson, \& Thollander, 2018; Tan, Tjandra, \& Song, 2015). Besides, SEC can be used indirectly to calculate the value of energy efficiency index (EEI). The deviation between the actual value of SEC and the standard value of SEC is a guide to explore the improvement chances when the best available EE practices are established (Lawrence et al., 2019).

A lot of research related to brewery industry focus on EE, include both electricity and thermal EE measures (Kubule, Zogla, Ikaunieks, \& Rosa, 2016) to reduce the energy demand consumption of the production processes (Muster-Slawitsch, Weiss, Schnitzer, \& Brunner, 2011). It is reported that the energy consumption on beer brewing is intensive production, energy costs up to $8 \%$ of total production costs (Pettigrew, Blomenhofer, Hubert, Groß, \& Delgado, 2015; Sturm, Butcher, Wang, Huang, \& Roskilly, 2012). The energy benchmarking is established to ensure the targets of EE including collection and identification the energy consumption issues, eliminate them, and continuously improve (Kubule et al., 2016; Muster-Slawitsch, Hubmann, Murkovic, \& Brunner, 2014). However, in some breweries from developing 
countries the real specific energy demand per production unit is uncontrolled therefore hardly to identify the improvements even if benchmarks are known.

In summary, although several research have adopted some indicators for the progress of energy benchmarking to improved EE as EEI, energy intensity, and ISO system provides general principles and guidance on how an enterprise can setup energy performance indicators and energy baselines for measuring energy performance, publications on critical assessments EE using SEC are scare (Lawrence et al., 2019; Tan et al., 2015), especial in a mix-product such as beer and beverage industry. Therefore, this study presents the methodology of SEC using to assess EE performance as a key KPI of energy-related. The guideline of SEC calculation for the beer and beverage industry, the purposes are:

1. A production mix including instructions on how to manage SEC-data to include to: (i) guideline for enterprises for how to calculate current SEC-value based on last year's energy consumption delimitate scope/ areas, adequate metering system; (ii) convert energy consumption as well as the enterprise's products (iii); set up a database of energy consumption and products.

2. A guideline for enterprises on how to assess deviations between SEC-target and actual SEC-value with assessments that include but is not limited on energy efficiency for 7-8 key technologies in relevant sector.

3. A guideline for how to prepare an annual plan to bring current SEC-value closer to the calculated SEC-target; and a roadmap for improving SEC-target closer to the mandatory SEC of Circulars for next 3 or 5 years.

\section{Research approach}

The aims of this study are to determine the methodology of SEC value target in the industry of beer and beverage in the condition of Vietnam on production characteristic and database available. The SEC target is the maximum allowable specific energy consumption for the site according to the LEEC-legislation of Vietnam (Ministry of Industry and Trade, 2016). The unit used for the specific energy consumption is $\mathrm{MJ} / \mathrm{hl}$ or million joules per hundred liters. In the circulars it is referred to as a "Norm" or "Quota". The SEC target is a function of both the energy consumption at the site and the production mix. The SEC target is determined for a full year's production volume and thus all data necessary to determine the SEC target should be available for the full year. The year for which the data is gathered is defined as the reporting year. The SEC target is different depending on the production-mix and the year in focus. The first step in assessing the site's SEC target is to choose one of the following site production 
categories: The site is only producing beer; The site is only producing beverage; The site is producing both beer \& beverage. Generally SEC is calculated as a ratio of energy used for producing a product (Farla et al., 1997):

$$
S E C=\frac{\text { Energy used }}{\text { Product's amount }}
$$

The SEC calculation in the case of mix-production of beer and beverage is also based on the equation (1), and insert the production volume weighting and equivalent product. Calculations of both of the variables "energy" and "product" are based on assumptions. One of the assumptions regards the definition of "equivalent product" because there are many types and grades of products for both beer and beverage. Besides, the SEC calculation used for this study approaching is based on the conditional of Vietnam beer and beverage industry on database available.

The procedure of establish SEC as a KPI for EE indicators of this study is implemented through 3 stages including: Step 1. Determine the SEC target; Step 2. Determine current SEC value; Step 3. Determine SEC improvement.

\section{SEC determination for beer and beverage production in Vietnam}

\subsection{Determine SEC target}

\subsubsection{SEC for beer producer only}

For a site producing only beer, two main inputs are necessary to determine the SEC target, they are presented in Table 1 . The origin year of data should be the most recent completed year. E.g. if the calculation is carried out in spring 2022 the reporting year should be 2021. The other input is the total beer production capacity, in million liters, on the site for the reporting year.

Table 1. Necessary input data to determine site SEC targets for beer production

\begin{tabular}{l|l|c}
\hline Parameter Name & Description & Unit \\
\hline Reporting year & The origin year of the data & $y$ \\
\hline Production Capacity & Total site capacity of beer production during reporting year & $10^{6} 1 / \mathrm{y}$ \\
\hline
\end{tabular}

Source: Circular 19/2016/TT-BCT 
This includes all beer whether it is leaving the site in cans, bottles or as draught beer. Based on the capacity and the reporting year the SEC target can be looked up in Circular 19/2016/TT-BCT, please also see table 2 as below.

Table 2. Beer specific energy consumption targets

\begin{tabular}{c|c|c|c}
\hline \multirow{2}{*}{$\begin{array}{c}\text { SEC } \\
\text { Taret, beer } \\
{[\mathrm{MJ} / \mathrm{hl}]}\end{array}$} & \multicolumn{2}{c}{ Reporting Year } \\
\cline { 3 - 4 } & $>100$ & 140 & {$[2021 ; 2025]$} \\
\hline \multirow{3}{*}{$\begin{array}{c}\text { Beer Capacity } \\
{\left[\mathbf{1 0}^{6} \mathrm{1} / \mathrm{y}\right]}\end{array}$} & {$[20-100]$} & 215 & 129 \\
\cline { 2 - 4 } & $<20$ & 306 & 196 \\
\cline { 2 - 4 } & $<2020]$ & 286 \\
\hline
\end{tabular}

Source: Circular 19/2016/TT-BCT

\subsubsection{SEC for beverage producer only}

For a site producing only beverage, two main inputs are necessary to determine the SEC target, they are presented in table 3. The origin year of data should be the most recent completed year. Example: if the reporting is carried out in spring 2022, the reporting year should be 2021. The other input is the product composition, three categories are possible:

- only still beverage production,

- only fizzy beverage production,

- both fizzy and still (mix) beverage production.

The production capacity is not used to determine SEC target for beverage. Based on the reporting year and the chosen product composition category, the SEC target can be looked up in Circular 19/2016/TT-BCT and also found from Table 3 below. Do notice that whether a site produces only fizzy beverage or a mix, the SEC target is the same.

Table 3. Necessary input data to determine site SEC targets for beverage production

\begin{tabular}{l|l|c}
\hline Parameter Name & Description & Unit \\
\hline Reporting year & The origin year of the data & y \\
\hline Product Composition & Type of beverage produced, can be: fizzy, still or both. & - \\
\hline
\end{tabular}

Source: Circular 19/2016/TT-BCT

41

NGUYEN DAT MINH 
Table 4. Beverage SEC Targets, mix should be interpreted as combined Fizzy and Still production

\begin{tabular}{c|c|c|c}
\hline \multirow{2}{*}{$\begin{array}{c}\text { SEC } \\
\text { Target, beverage } \\
[\mathrm{M}] / \mathrm{hl}]\end{array}$} & \multicolumn{2}{c}{ Interval } \\
\cline { 2 - 4 } & Fizzy or Mix & 55 & {$[2019 ; 2020]$} \\
\hline \multirow{2}{*}{ Product Composition } & Still & 111 & 107 \\
\cline { 2 - 4 } & & 52 & $125]$ \\
\hline
\end{tabular}

Source: Circular 19/2016/TT-BCT

\subsubsection{SEC for both beer and beverage producer}

If the site produces both beer and beverage the Circular 19/2016/TT-BCT do not state a SEC Target directly and thus the SEC target must be calculated as a weighted SEC target, using the method described in this section. For sites producing both beer and beverage, the method to determine the site SEC target consists of the following steps:

1. A SEC Target is determined based on the beer production.

2. A SEC Target is determined based on the beverage production.

3. The SEC Targets are combined using the site production volumes.

Five main inputs are necessary, they are presented in Table 5. The origin year of data should be the most recent completed year. E.g. if the reporting is carried out in spring 2022, the reporting year should be 2021. The capacity of the beer production equipment should be known for the reporting the year. The total production of beer, fizzy beverage and still beverage, in million liters, for the site should be known for the full reporting year.

Table 5. Necessary input data to determine site SEC targets for sites producing both beer and beverage

\begin{tabular}{l|l|c}
\hline Parameter Name & Description & Unit \\
\hline Reporting year & The origin year of the data & $y$ \\
\hline Beer Production Capacity & Total site capacity of beer production during reporting year & $10^{6} 1 / y$ \\
\hline Beer Production Volume & Total site production of beer during reporting year & $10^{6} 1 / y$ \\
\hline Still Beverage Production & Total site production of still beverage during reporting year & $10^{6} 1 / y$ \\
\hline Fizzy Beverage Production & Total site production of fizzy beverage during reporting year & $10^{6} 1 / y$ \\
\hline
\end{tabular}

Source: Circular 19/2016/TT-BCT 
Beer SEC target. For the beer production, only the reporting year and the beer production capacity are used. Based on these, it is possible to determine the SEC target using table 6 .

Table 6. Beer specific energy consumption targets

\begin{tabular}{c|c|c|c}
\hline \multirow{2}{*}{$\begin{array}{c}\text { SEC } \\
\text { Taret, beer } \\
{[\mathrm{MJ} / \mathrm{hl}]}\end{array}$} & \multicolumn{2}{c}{ Reporting Year } \\
\cline { 3 - 4 } & $>100$ & {$[2016 ; 2020]$} & {$[2021 ; 2025]$} \\
\hline \multirow{3}{*}{$\begin{array}{c}\text { Beer Capacity } \\
{\left[10^{6} \mathrm{l} / \mathrm{y}\right]}\end{array}$} & {$[20-100]$} & 215 & 129 \\
\cline { 2 - 4 } & $<20$ & 306 & 196 \\
\hline
\end{tabular}

Source: Circular 19/2016/TT-BCT

Beverage SEC target. Based on the reporting year and the site production composition, it is possible to determine the SEC target for beverage. The production volumes of fizzy and still beverage will not be needed until later. The product composition can be in one of three categories: (1) Only still beverage production; (2) Only fizzy beverage production; (3) Both Fizzy and still (mix) beverage production.

Based on the reporting year and the chosen product composition category the SEC target can be found from table 7.

Table 7. Beverage SEC targets, mix should be interpreted as combined Fizzy and Still production

\begin{tabular}{c|c|c|c}
\hline \multirow{2}{*}{$\begin{array}{c}\text { SEC } \\
\text { Target, beverage } \\
[M] / h l]\end{array}$} & {$[2016 ; 2020]$} & {$[2021 ; 2025]$} \\
\cline { 3 - 4 } & Fizzy or Mix & 55 & 52 \\
\cline { 2 - 4 } $\begin{array}{c}\text { Product } \\
\text { Composition }\end{array}$ & Still & 111 & 107 \\
\hline
\end{tabular}

Source: Circular 19/2016/TT-BCT

Combining beer \& beverage SEC targets. In order to obtain a single SEC for an entire production site, it is necessary to combine beer \& beverage SEC targets. 
This can be carried out by weighting the two SECs with production volumes. The necessary inputs are presented in table 8.

Table 8. Necessary input data to determine site energy target, all values should be for the period of the given reporting year

\begin{tabular}{l|l|c}
\hline Parameter Symbol & Description & Unit \\
\hline SEC & SEC target for beer as determined from section 4.1 .1 & $\mathrm{MJ} / \mathrm{hl}$ \\
\hline SEC & SEC target for beverage as determined from section 4.1 .2 & $\mathrm{MJ} / \mathrm{hl}$ \\
\hline$p_{\text {Beer }}$ & Total site production of beer & $10^{6} 1$ \\
\hline$p_{\text {beverage,1 }}$ & Total site production of still beverage & $10^{6} 1$ \\
\hline$p_{\text {beverage, }}$ & Total site production of fizzy beverage & $10^{6} 1$ \\
\hline
\end{tabular}

Source: Circular 19/2016/TT-BCT

The formula for determining the total site SEC target is then:

$\mathrm{SEC}_{\text {Target,total }}=\frac{p_{\text {Beer }} \cdot \mathrm{SEC}_{\text {Target,beer }}+\mathrm{SEC}_{\text {Target,beverage }} \cdot\left(p_{\text {beverage }, 1}+p_{\text {beverage }, 2}\right)}{p_{\text {Beer }}+p_{\text {beverage }, 1}+p_{\text {beverage }, 2}}$

\subsection{Determine current SEC value}

In order to analyze if the site is meeting the SEC target the actual current SEC value for the site must be determined using the method described in this section. The current SEC value for a facility is a calculation of the current (last years) specific energy consumption based on the current (last years) production mix. To make a calculation of current SEC value, the site energy consumption has to be compared to an equivalent production volume for the reporting year (last year). Special care has to be made in regard to production mix as a weighting is applied to the different type of products. 


\subsubsection{Current SEC value for beer or beverage producer only}

In order to determine the current SEC value for a given production site, the following steps must be completed:

- calculating site energy consumption in production areas,

- calculating site equivalent product based on the production mix and data in Circular 19/2016/TT-BCT,

- calculating current SEC value.

Energy Consumption. The total energy consumption for the site must be evaluated in a thermal and an electric parameter as shown in table 9. It is important to note that by "production areas" only include areas related to the regulated product (beer or beverage) should be included. If the site has a production line of another regulated product (plastic bottle/can production etc.), the energy consumption related to this area should not be included in the SEC value calculation for the beer/beverage production.

Table 9. Energy parameters description, all values should be for the period of the given reporting year

\begin{tabular}{l|l|c}
\hline Parameter Symbol & Description & Unit \\
\hline$E_{1, B e e r} /$ Beverage & Beer/Beverage electric energy consumption in production areas & MJ \\
\hline$T_{1, \text { Beer } / \text { Beverage }}$ & Beer/Beverage thermal energy consumption in production areas & MJ \\
\hline
\end{tabular}

Source: Circular 19/2016/TT-BCT

The site's electricity consumption consists of the electricity used by all the equipment in the production areas. There are different ways of finding the electricity consumption:

- sum electricity meter readings for transformers around the plant,

- use the site electricity total bill together with the "95\%-rule" as described below.

The site's electricity consumption in the beer production areas $\left(E_{1, B e e r} E_{1, B e e r}\right.$ (Beverage) can be approximated as $95 \%$ of the site's full electricity consumption (according to Circular 19/2016/TT-BCT). Usually, electricity is measured in the unit $k W h$ whereas the calculations of the SEC value require the energy to be in the unit $M J$. 
Now that the electricity consumption has been determined, the sites thermal energy consumption in the beer production areas $\left(T_{1, \text { Beer }} T_{1, \text { Beer } / \text { Beverage }}\right)$ has to be calculated.

$T_{1, \text { Beer }} T_{1, \text { Beer } / \text { Beverage }}$ is the sum of the energy contents of all fuels used in production areas on site in addition to any steam imported. An easy way to keep check of everything is to establish a list of fuels and steam consumption:

1. Heating Source Type: Determine which fuels are used on site, and whether the site has steam import or not. If steam is imported, the absolute pressure of the steam has to be determined in order to use the correct energy content. The easiest way to find the quantities is usually by checking the fuel invoices.

2. Heating Source Quantity: Determine the yearly consumption of each of the fuels including imported steam, the amount has to be in the unit of tones.

3. Energy Content: Find the energy content for each of the fuels in the established list using the figures listed in Circular 19/2016/TT-BCT. In Circular 19 /2016/ TT-BCT the most common fuels are stated. If the fuel used by the enterprise cannot be found in the table, the enterprise should contact the provincial DOIT in order to get the energy content of the specific fuel.

4. Energy Consumption: Multiply the energy content by the quantity of each fuel (and steam import) to establish the energy consumption for the year of each of the fuels.

5. Total Energy Consumption: Sum all of the fuel and steam energy consumptions to one total site energy consumption for the year, which is


below.

6.

$$
\begin{gathered}
T_{1, \text { Beer }}=\text { Heating Source Quantity } \\
\cdot \cdot \text { Energy Content }_{1}+\text { Heating Source Quantity }_{2} \\
\cdot \text { Energy Content } t_{2} \ldots
\end{gathered}
$$

Or

$$
\begin{aligned}
T_{1, \text { Beverage }}= & \text { Heating Source Quantity }{ }_{1} \cdot \text { Energy Content }_{1} \\
& + \text { Heating Source Quantity }_{2} \cdot \text { Energy Content }_{2} \ldots
\end{aligned}
$$

Equivalent Product. Instead of using the production volumes directly, a weighting is applied. The first step is to find the actual production of beer in three different categories as shown in table 10. 
Table 10. Production quantities necessary to determine the SEC value

\begin{tabular}{c|l|c}
\hline Parameter Symbol & Description & Unit \\
\hline$p_{\text {Beer }}$ & Total site production of beer & $\mathrm{hl}$ \\
\hline$p_{\text {Beer }, 1}$ & Total site production of bottled beer & $\mathrm{hl}$ \\
\hline$p_{\text {Beer }, 2}$ & Total site production of canned beer & $\mathrm{hl}$ \\
\hline$p_{\text {Beer }, 3}$ & Total site production of draught beer & $\mathrm{hl}$ \\
\hline
\end{tabular}

Source: Circular 19/2016/TT-BCT

An equivalent product volume for beer production can then be computed. Do notice that two different equivalent product volumes are calculated. The first volume relates to thermal energy consumption $P(T)_{B e e r} P(T)_{B e e r}$ and the second volume relates to electric energy consumption $P(E)_{B e e r} P(E)_{B e e r}$. They can be computed in the following way (according to Circular 19/2016/TT-BCT):

$$
\begin{aligned}
& P(T)_{\text {Beer }}=p_{\text {Beer }, 1}+p_{\text {Beer }, 2} \cdot 0.59+p_{\text {Beer }, 3} \cdot 0.8 \mathcal{E} \\
& P(E)_{\text {Beer }}=p_{\text {Beer }, 1}+p_{\text {Beer }, 2} \cdot 0.72+p_{\text {Beer }, 3} \cdot 0.91
\end{aligned}
$$

The actual production of beverage in six different categories as shown in table 11.

Table 11. Production quantities necessary to determine the SEC value

\begin{tabular}{c|l|c}
\hline Parameter Symbol & Description & Unit \\
\hline$p_{\text {beverage,1 }}$ & Total site production of fizzy beverage & $\mathrm{hl}$ \\
\hline$p_{\text {beverage,2 }}$ & Total site production of still beverage & $\mathrm{hl}$ \\
\hline$p_{\text {beverage,3 }}$ & $\begin{array}{l}\text { Total site production of bottled soft drinks (disposable } \\
\text { bottles) }\end{array}$
\end{tabular}

47

NGUYEN DAT MINH 


\begin{tabular}{c|l|c}
\hline$p_{\text {beverage }, 4}$ & Total site production of bottled soft drinks (glass bottles) & $\mathrm{hl}$ \\
\hline$p_{\text {beverage }, 5}$ & Total site production of canned beverage & $\mathrm{hl}$ \\
\hline$p_{\text {beverage }, \epsilon}$ & Total site production of packaged soft drinks & $\mathrm{hl}$ \\
\hline
\end{tabular}

Source: Circular 19/2016/TT-BCT

An equivalent product volume for beverage production can then be computed, and the calculation method changes depending on the site production pattern. Choose between the following two categories:

1. The site produces both still and fizzy product: Beverage (Mix): If the site produces both fizzy and still product, the following equations can be used, using parameters defined in Table 14, to determine equivalent production volumes:

$$
\begin{aligned}
P(T)_{\text {Beverage }}= & 0.5 \cdot\left(p_{\text {Beverage }, 1}+p_{\text {Beverage }, 2} \cdot 0.96+p_{\text {Beverage }, 3}\right. \\
& \left.+p_{\text {Beverage }, 4} \cdot 3.89+p_{\text {Beverage }, 5}+p_{\text {Beverage }, 6}\right) \\
P(E)_{\text {Beverage }}= & 0.5 \cdot\left(p_{\text {Beverage }, 1}+p_{\text {Beverage }, 2} \cdot 1.31+p_{\text {Beverage }, 3}\right. \\
& \left.+p_{\text {Beverage }, 4}+p_{\text {Beverage }, 5} \cdot 0.99+p_{\text {Beverage }, 6}\right)
\end{aligned}
$$

2. The side produces either still or fizzy product: Beverage (Single): If the site produces either fizzy or still product, the following equations can be used, using parameters defined in Table 14, to determine equivalent production volumes:

$$
\begin{aligned}
& P(T)_{\text {Beverage }}=p_{\text {Beverage }, 3}+p_{\text {Beverage }, 4} \cdot 3.89+p_{\text {Beverage }, 5}+p_{\text {Beverage }, 6} \\
& P(E)_{\text {Beverage }}=p_{\text {Beverage }, 3}+p_{\text {Beverage }, 4}+p_{\text {Beverage }, 5} \cdot 0.99+p_{\text {Beverage }, 6}
\end{aligned}
$$

Current SEC Value. The specific energy consumption for beer and for beverage can now be calculated as:

$$
S E C_{\text {Value Beer }}=\frac{E_{1, \text { beer }}}{P(E)_{\text {Beer }}}+\frac{T_{1, \text { beer }}}{P(T)_{\text {Beer }}}
$$




$$
\begin{aligned}
& \text { Management } \\
& 2021 \\
& \text { Vol. 25, No. } 2 \\
& S E C_{\text {Beverage }}=\frac{E_{1, \text { Beverage }}}{P(E)_{\text {Beverage }}}+\frac{T_{1, \text { Beverage }}}{P(T)_{\text {Beveragt }}}
\end{aligned}
$$

SEC Deviation. To determine whether the enterprise meets the target set out in Circular 19/2016/TT-BCT, the deviation between the SEC target and the SEC value has to be calculated. If the deviation is negative, the enterprise has to make a plan for how to get close to the SEC Target.

In order to compare the current SEC value to the SEC target required by Circular 19/2016/TT-BCT, the following equation can be applied:

$$
\text { Deviation }=\frac{\text { SEC Target }- \text { Current SEC Value }}{\text { SEC Target }} \cdot 100 \%
$$

If the result of the calculated deviation is negative, it means the current SEC value does not abide by the SEC target. A positive deviation shows how many percent the current SEC value is below the SEC target.

\subsubsection{Current SEC value for beer and beverage producer}

In order to determine the current SEC value for a given production site, which produces both beer and beverage, the following steps must be completed:

1. Calculating site energy consumption in production areas and splitting it into consumption related to beer and consumption related to beverage.

2. Calculating site equivalent product for both beer and beverage, based on the production mix and data in Circular 19/2016/TT-BCT.

3. Calculating SEC values for both beer and beverage and combining them into one.

Energy Consumption. The energy consumption for the site is evaluated in a thermal and an electric parameter as shown in table 12. Furthermore, the energy has to be split into energy consumed in order to produce beer and energy consumed in order to produce beverage. It is important to note that by "production areas" only areas related to the regulated product (beer and beverage) should be included. If the site has a production line of another regulated product (plastic bottle production etc.), the energy consumption related to this area should not be included in the SEC calculation for the beer and beverage production. 
Table 12. Energy parameters description, all values should be for the period of the given reporting year

\begin{tabular}{c|l|c}
\hline Parameter Symbol & \multicolumn{1}{|c}{ Description } & Unit \\
\hline$E_{1}$ & Site electric energy consumption in production areas & MJ \\
\hline$T_{1}$ & Site thermal energy consumption in production areas & MJ \\
\hline$E_{1, \text { Beer }}$ & Beer electric energy consumption in production areas & MJ \\
\hline$T_{1, \text { Beer }}$ & Beer thermal energy consumption in production areas & MJ \\
\hline$E_{1, \text { Beverag } \epsilon}$ & Beverage electric energy consumption in production areas & MJ \\
\hline$T_{1, \text { Beverag } \epsilon}$ & Beverage thermal energy consumption in production areas & MJ \\
\hline
\end{tabular}

Source: Circular 19/2016/TT-BCT

Electricity: The site's electrical energy consumption consists of the electricity used by all of the equipment in production areas. There are different ways of finding the electrical consumption:

- Sum electricity meter readings for transformers around the plant.

- Use the site electricity bill total together with the "95\%-rule" as described below.

The site's electricity consumption in production areas $\left(E_{1} E_{1}\right)$ can be approximated as $95 \%$ of the site's full electricity consumption (according to Circular 19/2016/TT-BCT). Usually, electricity is measured in the unit $k W h$ whereas the calculations require the energy to be in the unit $M J$.

After the total electricity consumption in production areas on site has been established, it is necessary to split it into electricity consumption for beer production and electricity consumption for beverage production. By measuring electricity consumption going to the different production equipment lines, it should be possible to make the first split. For common equipment (used for both beer and beverage) such as compressed air, $\mathrm{CO}_{2}$ plants and refrigeration either measurements should be done, or a split based on calculations could be carried out. 
Some examples of calculations splits are listed:

1. Refrigeration: Examine the cooling demand for first beer and then beverage and distribute the electricity consumption accordingly.

2. Compressed air: Examine the equipment consuming compressed air, their design value air consumption and operating hours, distribute total electricity consumption accordingly.

3. $\mathrm{CO}_{2}$ : Look into the $\mathrm{CO}_{2}$ requirement for the different products and the expected consumption on each line. Distribute total electricity consumption accordingly.

Thermal: Now that the electricity consumption has been established, the sites thermal consumption in production areas $\left(T_{1} T_{1}\right)$ has to be calculated. $T_{1} T_{1}$ is a sum of the energy contents of all fuels used in production areas on site including any steam imported (The losses converting fuel to steam is an integrated part of the steam heating value). An easy way to keep check of everything is to establish a list of fuels and steam consumption:

1. Heating Source Type: Determine which fuels are used on site, and whether the site has steam import or not. If steam is imported, the absolute pressure of the steam has to be determined in order to use the correct energy content. The easiest way to find the quantities is usually by checking the fuel invoices.

2. Heating Source Quantity: Determine the yearly consumption of each of the fuels and the steam, the amount has to be in the unit of tones.

3. Energy Content: Find the energy content for each of the fuels in the established list.

4. Energy Consumption: Multiply the energy content by the quantity of each fuel (and steam import) to establish the energy consumption for the year of each of the fuels.

5. Total Energy Consumption: Sum all of the fuel and steam energy consumptions to one total site energy consumption for the year, which is then $T_{1} T_{1}$

The equation for $T_{1} T_{1}$ is also shown below:

$$
\begin{gathered}
T_{1}=\text { Heating Source Quantity }_{1} \cdot \text { Energy Content }_{1}+\text { Heating Source Quantity }_{2} \\
\cdot \text { Energy Content }_{2} \ldots
\end{gathered}
$$

After the total thermal energy consumption in production areas on the site has been established, it is necessary to split it into beer and beverage consumption. For individual boilers used in the production it is easy to assign 
the consumption to either product. For common systems either measurements or calculations must be carried out. Usually the fuel is burned centrally in a boiler and distributed as steam. Dividing energy consumption between the products can thus be done by:

- measuring steam going to production lines in key places,

- determining heating demand for the different processes and assigning fuel accordingly.

Equivalent Product. After the energy consumption has been properly established, the product volumes have to be corrected in order to calculate the correct SEC values as according to Circular 19/2016/TT-BCT. An equivalent product volume is calculated for both electricity and thermal energy. The calculation method is different for beer and for beverage. The necessary input parameters to carry out the calculation are listed in table 13.

Table 13. Production quantities necessary to determine the SEC value

\begin{tabular}{c|l|c}
\hline Parameter Symbol & Description & Unit \\
\hline$p_{\text {Beer }}$ & Total site production of beer & hl \\
\hline$p_{\text {Beer }, 1}$ & Total site production of bottled beer & hl \\
\hline$p_{\text {Beer }, 2}$ & Total site production of canned beer & hl \\
\hline$p_{\text {Beer }, 3}$ & Total site production of draught beer & hl \\
\hline$p_{\text {beverage,1 }}$ & Total site production of fizzy beverage & hl \\
\hline$p_{\text {beverage,2 }}$ & Total site production of still beverage & hl
\end{tabular}




\begin{tabular}{l|l|c}
\hline$p_{\text {beverage, } \epsilon}$ & Total site production of packaged soft drinks & $\mathrm{hl}$ \\
\hline
\end{tabular}

Source: Circular 19/2016/TT-BCT

The method includes the following two steps:

- two equivalent product volumes for beverage are calculated $\left.P(E)_{\text {Beverag } \epsilon} P(E)_{\text {Beverag } \epsilon} \& P(T)_{\text {Beverag } \epsilon} P(T)_{\text {Beverag } \epsilon}\right)$,

- two equivalent product volumes for beer are calculated $\left(P(E)_{\text {beer }}\right.$ $\left.P(E)_{b e e r} \& P(T)_{b e e r} P(T)_{b e e r}\right)$.

Beverage Equivalent Product Volumes. An equivalent product volume for beverage production has to be computed. Do notice that two different equivalent product volumes are calculated. The first volume relates to thermal energy consumption $P(T)_{\text {Beveragt }} P(T)_{\text {Beveragt }}$ and the second volume relates to electric energy consumption $P(E)_{\text {Beverag } \epsilon} P(E)_{\text {Beveragt }}$. Furthermore, the calculation method changes depending on the site production pattern. Choose between the following two categories:

1. The site produces both still and fizzy product: Beverage (Mix): If the site produces both fizzy and still product, the following equations can be used, using parameters defined in table 14, to determine equivalent production volumes:

$P(T)_{\text {Beverage }}=0.5 \cdot\left(p_{\text {Beverage }, 1}+p_{\text {Beverage }, 2} \cdot 0.96+p_{\text {Beverage }, 3}+p_{\text {Beverage }, 4} \cdot 3.89\right.$

$\left.+p_{\text {Beverage }, 5}+p_{\text {Beverage }, 6}\right)$

$P(E)_{\text {Beverage }}=0.5 \cdot\left(p_{\text {Beverage }, 1}+p_{\text {Beverage }, 2} \cdot 1.31+p_{\text {Beverage }, 3}+p_{\text {Beverage }, 4}\right.$ $\left.+p_{\text {Beverage }, 5} \cdot 0.99+p_{\text {Beverage }, 6}\right)$

2. The side produces either still or fizzy product: Beverage (Single): If the site produces either fizzy or still product, the following equations can be used, using parameters defined in Table 14, to determine equivalent production volumes:

$P(T)_{\text {Beverage }}=p_{\text {Beverage }, 3}+p_{\text {Beverage }, 4} \cdot 3.89+p_{\text {Beverage }, 5}+p_{\text {Beverage }, 6}$

$P(E)_{\text {Beverage }}=p_{\text {Beverage }, 3}+p_{\text {Beverage }, 4}+p_{\text {Beverage }, 5} \cdot 0.99+p_{\text {Beverage }, 6}$

Beer equivalent product volumes. An equivalent product volume for beer 
production can then be computed. Again, two different equivalent product volumes are calculated. The first volume relates to thermal energy consumption $P(T)_{\text {Beer }} P(T)_{\text {Beer }}$ and the second volume relates to electric energy consumption $P(E)_{B e e r} P(E)_{B e e r}$. They can be computed in the following way:

$$
\begin{aligned}
& P(T)_{\text {Beer }}=p_{\text {Beer }, 1}+p_{\text {Beer }, 2} \cdot 0.59+p_{\text {Beer }, 3} \cdot 0.8 \mathrm{C} \\
& P(E)_{\text {Beer }}=p_{\text {Beer }, 1}+p_{\text {Beer }, 2} \cdot 0.72+p_{\text {Beer }, 3} \cdot 0.91
\end{aligned}
$$

Current SEC Value. In order to calculate the current SEC value for the entire site, the following steps are carried out:

- a Current SEC Value for beer is calculated,

- a Current SEC Value for beverage is calculated,

- the Current total SEC Values are combined into one using a weighting.

Beer Current SEC Value. The Current SEC value for beer can now be calculated as:

$$
S E C_{\text {Beer }}=\frac{E_{1, \text { beer }}}{P(E)_{\text {Beer }}}+\frac{T_{1, \text { beer }}}{P(T)_{\text {Beer }}}
$$

Beverage Current SEC Value. The specific energy consumption for beverage can be calculated as:

$$
S E C_{\text {Beverage }}=\frac{E_{1, \text { Beverage }}}{P(E)_{\text {Beverage }}}+\frac{T_{1, \text { Beverage }}}{P(T)_{\text {Beverag } \epsilon}}
$$

Combining Current SEC Values. The SEC values for beverage and beer can be combined into a weighted total site wide SEC value using the following formula (with parameter definitions as in table 17):

$$
\mathrm{SEC}_{\text {Value,total }}=\frac{p_{\text {Beer }} \cdot \mathrm{SEC}_{\text {beer }}+\mathrm{SEC}_{\text {beverage }} \cdot\left(p_{\text {beverage }, 1}+p_{\text {beverage }, 2}\right)}{p_{\text {Beer }}+p_{\text {beverage }, 1}+p_{\text {beverage }, 2}}
$$

SEC Deviation. In order to compare the current SEC value to the SEC target required by Circular 19/2016/TT-BCT, the following equation can be applied:

$$
\text { Deviation }=\frac{\text { SEC Target }- \text { Current SEC Value }}{\text { SEC Target }} \cdot 100 \%
$$

Negative deviation means the current SEC value does not abide by the SEC target. A positive deviation shows how many percent the current SEC value is below the SEC target. The deviation shows that the site is significantly below target which indicates an energy efficient production. 


\subsection{SEC improvement}

A part of the reporting to describe the improvement of the current SEC Value from the previnic vaare Tho imnroviomont ran ho ralcilatod ac ctatod in Annex $\mathrm{B}$ to this guid'Improvement $=\frac{S E C_{\text {Previous Year }}-S E C_{\text {Present }}}{S E C_{\text {Previous Year }}} \cdot 100 \%$

Example: Continuing the example for beer and beverage production: Given that for the reporting year 2017 an $S E C_{\text {Value,total,2017 }}=120,6 S E C_{\text {Value,total,2017 }}=120,6$ was achieved. In the examnlo a SFC........ $=115$ aSFC......... $=115,9$ was achieved for 2018. The Improvement $=\frac{120,6-115,9}{120,6} \cdot 100 \%=3,9 \%$

\section{Conclusion}

This study presents the SEC methodology as a guide for Vietnam enterprises in the brewery sector on how to manage the EE consumption management and to comply with the national regulation mentioned in the Circular 19/2016/TTBCT on energy consumption quota in the beer and beverage production.

This proposition is based on the experience of the authors and have been developed in close cooperation with the MOIT and Danish Energy Agency in project No. 1874 DEPP II named "Capacity development on low carbon legal instruments for industry - DOIT administrative procedures". Additionally, the results of this study have been tested by the international consultant at two breweries in Vietnam in September 2019 and presented and discussed at a Consultation Workshops in December 2019.

In accordance with Circular 19/2016/TT-BCT all enterprises in the beer and beverage production industry have to report on their SEC value to the DOIT every year. If the SEC value does not abide by the SEC targets set out in the Circular, the enterprise additionally has to report a plan on how to reach the SEC target in the future. The Guidelines supports the enterprise in how to determine the SEC target, the SEC value, investigate possible energy saving projects and making an implementation plan depending on the product, production capacity. In the case of the SEC value does not abide by the SEC target, the enterprise has to make a detailed analysis of the key production technologies in order to investigate where and to what extent energy efficiency projects can be carried out.

Besides, the support for national EE is essential to the promotion and deployment of practical energy-saving solutions and compliance the SEC through a suitable 
energy-saving targets. Results and methodology developed from this study can form the basis to help other industries or developing countries like Vietnam in their development and implementation of the National Program on EE\&C.

\section{Summary}

\section{ENERGY BENCHMARKING MANAGEMENT FOR BEER AND BEVERAGE INDUSTRY IN VIETNAM}

The purpose of this paper is to introduce basic principles of benchmarking and explain the methodology to set the specific energy consumption (SEC) target for the beer and beverage industry in Vietnam to evaluate performance, support decisions, and energy efficiency (EE) improvement. Energy benchmarking management method is used to assess EE performance. This study also presents the SEC methodology as a guide for Vietnam enterprises in the brewery sector on how to manage the EE consumption and to comply with the legal energy consumption quota in the beer and beverage production. The study supports the enterprise in how to determine the SEC and support for national EE is essential to the promotion and deployment of practical energysaving solutions and compliance with the SEC through a suitable energy-saving target. In addition, this paper is introducing the original SEC calculation in three cases of production in the beer and beverage industry including producing beer only, producing beverage only, and producing both beer \& beverage in the context of Vietnam.

Keywords: Energy efficiency, Energy benchmarking, Specific energy consumption, Beer and beverage industry, Vietnam.

JEL: $\quad$ L53, L6, P18, Q43,

\section{References}

Assawamartbunlue, K., \& Luknongbu, W. (2020). Specific energy consumption of native starch industry in Thailand. Energy Reports, 6, 299303.

Assawamartbunlue, K., Surawattanawan, P., \& Luknongbu, W. (2019). Specific energy consumption of cement in Thailand. Energy Procedia, 156, 212-216. 
Bertoldi, P., \& Mosconi, R. (2020). Do energy efficiency policies save energy? A new approach based on energy policy indicators (in the EU Member States). Energy Policy, 139, 111320, 1-18.

Farla, J., Blok, K., \& Schipper, L. (1997). Energy efficiency developments in the pulp and paper industry: A cross-country comparison using physical production data. Energy Policy, 25(7-9), 745-758.

Fleiter, T., Fehrenbach, D., Worrell, E., \& Eichhammer, W. (2012). Energy efficiency in the German pulp and paper industry-A model-based assessment of saving potentials. Energy, 40(1), 84-99.

Gruber, E., Fleiter, T., Mai, M., \& Frahm, B. (2011). Efficiency of an energy audit programme for SMEs in Germany-results of an evaluation study. Proceedings of the European Council for an Energy Efficient Economy (ECEEE) Summer Study, Presqu'île de Giens, France, 5-10.

Hui, M., \& Wong, M. (2010, 2-3 July 2010). Benchmarking the energy performance of hotel buildings in Hong Kong. Paper presented at the Liaoning Hong Kong Joint Symposium. Dalian, China, Dalian, China.

Hui, S. C. (2010). Energy benchmarking for buildings and plant engineering. Paper presented at the Proceeding of the SOE Symposium.

Kubule, A., Zogla, L., Ikaunieks, J., \& Rosa, M. (2016). Highlights on energy efficiency improvements: a case of a small brewery. Journal of Cleaner Production, 138, 275-286.

Labandeira, X., Labeaga, J. M., Linares, P., \& López-Otero, X. (2020). The impacts of energy efficiency policies: Meta-analysis. Energy Policy, 147, 111790, 1-27.

Lawrence, A., Karlsson, M., \& Thollander, P. (2018). Effects of firm characteristics and energy management for improving energy efficiency in the pulp and paper industry. Energy, 153, 825-835.

Lawrence, A., Thollander, P., Andrei, M., \& Karlsson, M. (2019). Specific energy consumption/use (SEC) in energy management for improving energy efficiency in industry: Meaning, usage and differences. Energies, 12(2), 247.

Ministry of Industry and Trade of Vietnam. (2016). Circular No. 19/2016/ TT-BCT on energy consumption quota in the beer and beverage production industry

Mull, T. E. (2001). Practical guide to energy management for facilities engineers and managers. New York: Amer Society of Mechanical.

Muster-Slawitsch, B., Hubmann, M., Murkovic, M., \& Brunner, C. (2014). Process modelling and technology evaluation in brewing. Chemical Engineering and Processing: Process Intensification, 84, 98-108.

Muster-Slawitsch, B., Weiss, W., Schnitzer, H., \& Brunner, C. (2011). The green brewery concept-energy efficiency and the use of renewable energy sources in breweries. Applied Thermal Engineering, 31(13), 2123-2134. 
Pettigrew, L., Blomenhofer, V., Hubert, S., Groß, F., \& Delgado, A. (2015). Optimisation of water usage in a brewery clean-in-place system using reference nets. Journal of Cleaner Production, 87, 583-593.

Sontag, B., Hirzel, S., Bender, O., Kloos, H., Laubach, M., Wallkötter, R., \& Rohde, C. (2014). Energy-benchmarking within companies: insights from benchmarking practice. ECEEE-2014. Industrial summer study-retool for competitive and sustainable industry, P, 637-646.

Stapenhurst, T. (2009). The benchmarking book: Routledge.

Sturm, B., Butcher, M., Wang, Y., Huang, Y., \& Roskilly, T. (2012). The feasibility of the sustainable energy supply from bio wastes for a small scale brewery-A case study. Applied Thermal Engineering, 39, 45-52.

Tan, Y.S., Tjandra, T. B., \& Song, B. (2015). Energy efficiency benchmarking methodology for mass and high-mix low-volume productions. Procedia Cirp, 29, 120-125.

Tanaka, K. (2011). Review of policies and measures for energy efficiency in industry sector. Energy Policy, 39(10), 6532-6550.

Zhang, S., Worrell, E., Crijns-Graus, W., Krol, M., de Bruine, M., Geng, G., Cofala, J. (2016). Modeling energy efficiency to improve air quality and health effects of China's cement industry. Applied energy, 184, 574-593.

Zogla, L., Zogla, G., Beloborodko, A., \& Rosa, M. (2015). Process benchmark for evaluation energy performance in breweries. Energy Procedia, 72, 202208. 